\title{
Anabases
}

ANABASES Traditions et réceptions de l'Antiquité

\section{Vanda ZAJKO et Miriam LEONARD, eds. Laughing with Medusa. Cassical Myth and Feminist Thought}

\section{Violaine Sebillotte Cuchet}

\section{(2) OpenEdition}

\section{Journals}

Édition électronique

URL : http://journals.openedition.org/anabases/3250

DOI : 10.4000/anabases.3250

ISSN : 2256-9421

\section{Éditeur}

E.R.A.S.M.E.

\section{Édition imprimée}

Date de publication : 1 mars 2007

Pagination : 273-275

ISSN : 1774-4296

\section{Référence électronique}

Violaine Sebillotte Cuchet, «Vanda zasko et Miriam LEonARD, eds. Laughing with Medusa. Cassical Myth and Feminist Thought », Anabases [En ligne], 5 | 2007, mis en ligne le 01 décembre 2011, consulté le 22 septembre 2020. URL : http://journals.openedition.org/anabases/3250 ; DOI : https://doi.org/ 10.4000/anabases.3250

Ce document a été généré automatiquement le 22 septembre 2020

(c) Anabases 


\title{
Vanda ZAJKO et Miriam LEONARD, eds. Laughing with Medusa. Cassical Myth and Feminist Thought
}

\author{
Violaine Sebillotte Cuchet
}

\section{RÉFÉRENCE}

Vanda ZAJKO et Miriam LEONARD, eds. Laughing with Medusa. Cassical Myth and Feminist Thought, Oxford, Oxford University Press, 2006, $464 \mathrm{p}$.

55 \$ / ISBN 0-19-927438.

1 Comme la Méduse située par les Grecs aux marges de leur monde, les féministes ont développé un regard distancié, ironique et souvent moqueur, sur la civilisation androcentrée héritée de la Méditerranée antique. L'allusion au manifeste d'Hélène Cixous «Le Rire de la Méduse» rappelle que les mythes entendus au sens large de « récits fictifs » étayent les représentations les plus misogynes du féminin tout en nourrissant les perspectives féministes d'une société post-patriarcale. La première partie, "Mythe et psychanalyse", montre à quel point la notion freudienne de " différence sexuelle » constitue un obstacle pour les théoriciennes féministes. Rachel Bowlby ("The Cronus Complex: Psychoanalytic Myths of the Future for Boys and Girls ") montre avec finesse comment l'interprétation psychanalytique, qui destine les garçons à la civilisation censée protéger de la castration et renvoie les filles à la résignation, s'appuie sur des épisodes mythiques précisément isolés par Freud. Pour sauver le féminin de cette impasse les féministes ont pu choisir deux voies. Griselda Pollock («Beyond Oedipus: Feminist Thought, Psychoanalysis, and Mythical Figurations of the Feminine ») balise celle ouverte par l'hypothèse de Jane Harrison d'un principe féminin positif aux fondements de l'art occidental et des pratiques rituelles antiques. À l'opposé d'une telle approche, sensible dans l'œuvre de Bracha Ettinger, où le mythe sert d'archétype, d'autres développent une conception plus 
performative ainsi que le montre Vanda Zajko dans “ 'Who are we when we read ?' : Keats, Klein, Cixous and Elizabeth Cook's Achilles". Le processus d'identification à l'œuvre dans la lecture illustre le mécanisme de construction de soi analysé par Mélanie Klein : l'appartenance sexuelle devient un élément mineur et telle féministe peut se réaliser comme un nouvel Achille. Dans la deuxième partie, "Mythe et politique ", Miriam Leonard ("Lacan, Irigaray, and Beyond: Antigones and the Politics of Psychoanalysis ") dresse un panorama très éclairant sur la façon dont Luce Irigaray puis Judith Butler ont discuté la lecture misogyne d'Antigone par Lacan qui, après Hegel et d'une toute autre façon, exclut l'héroïne du politique. En revenant au texte de Sophocle dans "Antigone and the Politics of Sisterhood" Simon Goldhill éclaire cependant les failles de théories qui toutes isolent un personnage censé représenter La Femme et présupposent un politique abstrait, La Cité. Attentive au danger de lectures univoques, Katie Fleming montre dans "Fascism on Stage : Jean Anouilh's Antigone" à quel point le mythe est et reste polysémique. Dans la troisième partie, "Mythe et histoire ", Ellen O'Gorman avec "A Woman's History of Warfare” et Gregory Staley avec "'Beyond glorious Ocean' : Feminism, Myth, and America”, rappellent combien l'histoire traditionnelle s'écrit le plus souvent au moyen de catégories très genrées où la femme et le féminin renvoient à des stéréotypes frottés à la longue durée. Usant d'un langage comparable Hélène Cixous le retourne politiquement en décrivant son siècle comme celui d'une nouvelle Renaissance, celle de la Découverte du corps féminin, par les femmes. La partie "Mythe et science " présente à la fois la critique féministe de la notion de vérité scientifique, assimilée à un réductionnisme ("Atoms, Individuals, and Myths " par Duncan Kennedy), une analyse du De Rerum Natura de Lucrèce qui propose une généalogie du regard masculin sur le monde ("The Philosopher and the Mother Cow : Towards a Gendered Reading of Lucretius, De Rerum Natura " par Alison Sharrock), et une présentation d'une des dernières utopies féministes opérantes dans la pensée théorique actuelle, celle développée par Donna Haraway de l'individu comme chimère, constitué d'une juxtaposition d'identités (appartenance de classe, de sexe, de race, etc.). Geneviève Liveley conclut heureusement son article "Science Fictions and Cyber et Myths : or, Do Cyborgs Dream of Dolly the Sheep?" en rappelant la nécessité de reconstruire cette identité éclatée. La dernière partie "Mythe et poésie" développe dans le champ littéraire les voies rencontrées plus haut. Ainsi Lillian Doherty dans "Putting the Women Back into the Hesiodic Catalogue of Women " plaide de façon assez convaincante pour la prise en compte d'une tradition orale féminine antique. Penny Murray dans "Reclaiming the Muse" souligne la signification parfois très positive d'une créativité féminine dont Sappho offre l'exemple le mieux connu pour l'Antiquité. Efi Spentzou ("Defying History: The Legacy of Helen in Modern Greek Poetry") analyse la réception d'Hélène dans la poésie grecque moderne en en soulignant les appropriations contradictoires. L'étude de Rowena Fowler sur la façon dont des poétesses contemporaines Jorie Graham et Eavan Boland utilisent les mythes et la notion ovidienne de métamorphose (“'this tart fable' : Daphne, and Apollo in Modern Women's Poetry ") rejoint les voies ouvertes dans la première partie sur la question de l'identification à l'œuvre dans le processus de lecture. Pour finir, le joli récit d'Elizabeth Cook “Iphigeneia's wedding " explore à sa façon la symbolique du sang et des rapports mère-fille.

2 La lecture critique d'ensemble, choix éditorial, souligne à quel point l'usage du mythe est ambivalent : il clôt les interprétations lorsque lui est conférée l'autorité de l'ancien, de l'universel, voire du primordial, mais les ouvre aussi puisque sa plasticité autorise 
leur diversité. Ce livre donne ainsi une bonne idée de la richesse, de la pluralité, et des difficultés rencontrées par la théorie féministe actuelle ainsi que de la façon dont l'Antiquité classique est sans cesse mobilisée, de part et d'autre, et plus ou moins honnêtement.

\section{AUTEURS}

\section{VIOLAINE SEBILLOTTE CUCHET}

Université Paris I - Équipe Phéacie

violaine.sebillotte@univ-paris1.fr 